\title{
Increasing glucose demand increases hepatic pyruvate carboxylase mRNA concentration but not feed intake in late-lactation dairy cows*
}

\author{
B.J. Bradford and M.S. Allen ${ }^{1}$ \\ Department of Animal Science, Michigan State University \\ East Lansing, Michigan 48824, USA
}

\begin{abstract}
To determine if increased glucose demand affects feed intake or hepatic metabolism, 12 lactating Holstein cows were treated with phlorizin or control in a crossover experiment. Phlorizin injected subcutaneously at $4 \mathrm{~g} / \mathrm{d}$ caused $474 \mathrm{~g} / \mathrm{d}$ of glucose excretion in urine. While treatment caused a decrease in lactose synthesis and milk production, feed intake and 3.5\% fat-corrected milk production were not altered by treatment. The lost glucose was likely accounted for by increased gluconeogenic flux. Hepatic pyruvate carboxylase mRNA concentration increased with phlorizin treatment, suggesting that retention of glucose precursors may be involved in regulation of gluconeogenesis.
\end{abstract}

KEY WORDS: glucose demand, gluconeogenesis, pyruvate carboxylase, phlorizin, propionate

\section{INTRODUCTION}

Glucose demand may play an important role in determining the level of feed intake in lactating dairy cattle. Increasing milk production, via genetics or somatotropin treatment, is correlated with increases in voluntary DMI. Increasing glucose demand can decrease the molar insulin:glucagon ratio, resulting in enhanced flux through gluconeogenic pathways. This may increase the proportion of propionate that is utilized for glucose production and limit propionate oxidation. If high hepatic ATP concentrations cause the initiation of vagal-mediated satiety signals, decreased propionate oxidation may increase DMI (Allen, 2000). We

\footnotetext{
* This material is based upon work supported under a National Science Foundation Graduate Research Fellowship and supported by the Cooperative State Research, Education, and Extension Service, U.S. Department of Agriculture, under Agreement No. 2004-35206-14167

${ }^{1}$ Corresponding author: e-mail: allenm@msu.edu
} 
used phlorizin to experimentally alter glucose demand and assessed the results on milk and milk component production, feeding behaviour, hepatic gene expression, and blood composition. We hypothesized that feed intake and mRNA concentrations for genes involved in glucose metabolism would be enhanced by phlorizin treatment.

\section{MATERIAL AND METHODS}

\section{Experimental design}

Twelve multiparous lactating Holstein cows (269 \pm 65 DIM) were randomly assigned to treatment sequence in a crossover design. Phlorizin, an inhibitor of renal glucose reabsorption, was administered via intramuscular injection at the rate of $4 \mathrm{~g}$ /day, with propylene glycol as the carrier and control. Injections were given every $6 \mathrm{~h}$ for $7 \mathrm{~d}$, with a 7 -d rest period prior to each treatment period. Throughout the experiment, all cows were fed a diet containing maize silage and lucerne haylage at a 1:1 ratio, dry ground maize grain, and protein and mineral/ vitamin premixes. The diet contained $28 \% \mathrm{NDF}, 16 \% \mathrm{CP}$, and $33 \%$ starch on a dry matter basis. Data was collected during the final 4 days of each injection period. Feeding behaviour was continuously monitored by a computerized data acquisition system and analysed to determine average meal size, meal length, and intermeal interval for each day. Milk yield was recorded daily and milk samples were analysed for fat, protein, and lactose content. Jugular blood was collected from an indwelling catheter every hour for a $24 \mathrm{~h}$ period. Plasma was harvested and analysed for glucose, $\beta$-hydroxybutyrate (BHBA), non-esterified fatty acids (NEFA), insulin, and glucagon. Urinary catheters were inserted and kept in place for a $24 \mathrm{~h}$ period for total urine collection, and urine volume and glucose concentration was measured. Faecal samples were collected 3 times at 8 $\mathrm{h}$ intervals and were analysed, along with feed and orts samples, for ash, starch, NDF, indigestible NDF, and protein content.

\section{Gene expression analysis}

Liver tissue was harvested by needle biopsy immediately prior to initial phlorizin treatment and following the final phlorizin injection on day 7 of the treatment period. Tissue was frozen in liquid nitrogen immediately after biopsy and stored at $-80^{\circ} \mathrm{C}$ until processing. RNA was isolated using a commercial kit (RiboPure, Ambion, Inc., Austin, TX) and was treated with DNase to remove any DNA contamination. Quality of all RNA isolates was verified by analysis with an Agilent 2100 Bioanalyzer (Agilent Technologies, Palo Alto, CA).

Messenger RNA of cytosolic phosphoenolpyruvate carboxykinase (PEPCK), glucose-6-phosphatase (G6Pase), pyruvate carboxylase (PC), and pyruvate dehydrogenase kinase 4 (PDK4) was analysed by quantitative real-time reverse 
transcriptase polymerase chain reaction (qRT-PCR) using a commercial kit (Superscript III Platinum Two-Step qRT-PCR Kit, Invitrogen, Carlsbad, CA). Reverse transcription was carried out using oligo-dT primers with $1 \mu \mathrm{g}$ total RNA added as template. Following RNase H treatment, the cDNA product was quantified by spectrophotometer. Real-time PCR was carried out in duplicate using $1 \mu \mathrm{g}$ cDNA and was monitored using the ABI Prism 7000 Sequence Detection System (Applied Biosystems, Foster City, CA). LUX primers and complementary unlabeled primers (Invitrogen, Carlsbad, CA) were designed with online LUX Designer software. Copy numbers for each gene were measured with 2 separate qRT-PCR analyses using cDNA template from unique reverse transcription reactions. Standard curves were produced for each gene of interest to allow for absolute quantification (Whelan et al., 2003). Messenger RNA concentration was normalized using the geometric mean of copy numbers of cyclophilin, betaactin, and phosphoglycerate kinase 1 in each sample (Vandesompele et al., 2002). Quantification of copy numbers for control genes was carried out in the manner described above.

\section{Statistical analysis}

Data was analysed by mixed models including random effects of cow and fixed effects of treatment, period, treatment by period interaction, and PCR plate where appropriate. Significance was declared at $\mathrm{P}<0.05$, and tendencies at $\mathrm{P}<0.10$. Data for gene expression of PEPCK was log-transformed for analysis, and treatment effects reported here are based on back-transformed LS means.

\section{RESULTS AND DISCUSSION}

Phlorizin caused a significant increase in irreversible glucose loss, as daily loss in urine averaged $474 \mathrm{~g} / \mathrm{d}$ in treated cows compared with $1 \mathrm{~g} / \mathrm{d}$ in controls. Dry matter intake was not altered by phlorizin treatment, nor was any measure of feeding behaviour. Although milk production was decreased by phlorizin (24.9 vs $22.8 \mathrm{~kg} / \mathrm{d} ; \mathrm{P}=0.001), 3.5 \%$ fat-corrected milk production was not; phlorizin caused a significant depression in lactose production but not milk fat production. Lactose production accounted for approximately $90 \mathrm{~g} / \mathrm{d}$ of the glucose lost in urine, but $384 \mathrm{~g} / \mathrm{d}$ remained unaccounted for, because digestible starch intake was not altered by treatment.

Veenhuizen et al. (1988) increased the proportion of propionate used for glucose production by $35 \%$ by administering phlorizin at $2 \mathrm{~g} / \mathrm{d}$ in steers, suggesting that changes in peripheral glucose demand can greatly impact gluconeogenesis. Our data supports this conclusion. While phlorizin-treated animals likely decreased glucose uptake in muscle and adipose tissue, it seems unlikely that this effect could account for a substantial proportion of the glucose lost. This leaves 
enhanced gluconeogenesis as the most likely source of the additional glucose. The molar insulin:glucagon ratio was decreased by phlorizin $(\mathrm{P}<0.001)$, and copies of PC mRNA were increased by $102 \%(\mathrm{P}<0.001)$. Phlorizin treatment also tended to increase PEPCK mRNA concentration by $38 \%(\mathrm{P}=0.08$ normalized, $\mathrm{P}>0.10$ without control gene normalization), but treatments did not differ in G6Pase or PDK4 mRNA concentrations. While the importance of PEPCK in regulation of gluconeogenesis is well recognized, $\mathrm{PC}$ also plays an important role in ruminant glucose metabolism because it conserves carbon units in gluconeogenic pathways. Propionate metabolism can result in the rapid production of pyruvate, which can be irreversibly directed toward oxidation by pyruvate dehydrogenase if PC activity is low.

The lack of DMI response to an increase in glucose demand was unexpected. However, the increase in plasma NEFA due to treatment $(100.1$ vs $70.0 \mu \mathrm{M}$; $\mathrm{P}<0.001)$ makes it impossible to reject the hypothesis that intake is regulated by hepatic ATP production. The liver takes up NEFA in proportion to its concentration in plasma, so phlorizin likely caused an increase in hepatic NEFA oxidation. Additionally, amino acids could have served as a source of energy or glucose precursors. These nutrients may have been oxidized rapidly enough to compensate for lower production of ATP from decreased propionate oxidation.

\section{CONCLUSIONS}

Increasing peripheral glucose demand in late-lactation dairy cows did not increase feed intake and had a minimal impact on milk production. Adaptations by the liver to increase glucose production included increased pyruvate carboxylase mRNA concentrations.

\section{REFERENCES}

Allen M.S., 2000. Effects of diet on short-term regulation of feed intake by lactating dairy cattle. J. Dairy Sci. 83, 1598-1624

Vandesompele J., De Preter K., Pattyn F., Poppe B., Van Roy N., De Paepe A., Speleman F., 2002. Accurate normalization of real-time quantitative RT-PCR data by geometric averaging of multiple internal control genes. Genome Biol. 3, RESEARCH0034

Veenhuizen J.J., Russell R.W., Young J.W., 1988. Kinetics of metabolism of glucose, propionate and $\mathrm{CO} 2$ in steers as affected by injecting phlorizin and feeding propionate. J. Nutr. 118, 1366-1375

Whelan J.A., Russell N.B., Whelan M.A., 2003. A method for the absolute quantification of cDNA using real-time PCR. J. Immunol. Method. 278, 261-269 